\title{
Length of Hospital Stay for Osteoarthritic Primary Hip and Knee Replacement Surgeries in New Zealand
}

\author{
Chunhuan Lao ${ }^{1, *}$, David Lees ${ }^{2}$, Sandeep Patel ${ }^{3}$, Douglas White ${ }^{4}\left(\mathbb{D}\right.$ and Ross Lawrenson ${ }^{1,5}$ \\ 1 Waikato Medical Research Centre, The University of Waikato, Hamilton 3240, New Zealand; \\ ross.Lawrenson@waikatodhb.health.nz \\ 2 Orthopaedic Department, Tauranga Hospital, Tauranga 3143, New Zealand; dlee078@gmail.com \\ 3 Orthopaedic Department, Waikato Hospital, Hamilton 3240, New Zealand; \\ sandeep.patel@waikatodhb.health.nz \\ 4 Rheumatology Department, Waikato Hospital, Hamilton 3240, New Zealand; \\ douglas.white@waikatodhb.health.nz \\ 5 Strategy and Funding, Waikato District Health Board, Hamilton 3240, New Zealand \\ * Correspondence: chunhuan.lao@waikato.ac.nz; Tel.: +64-(0)-7-837-9485
}

Received: 22 October 2019; Accepted: 27 November 2019; Published: 29 November 2019

\begin{abstract}
This study aims to explore the length of stay (LOS) of publicly funded osteoarthritic primary hip and knee replacement surgeries in New Zealand. Patients with osteoarthritis who underwent publicly funded primary hip and knee replacement surgery in 2005-2017 were included. We have identified 53,439 osteoarthritic primary hip replacements and 50,072 osteoarthritic primary knee replacements. LOS has been reduced by almost $40 \%$ over the last 13 years. Logistic regression showed that women, Māori, Pacific and Asian patients, older patients, people with more comorbidities and those having opiates on discharge and patients in earlier years were more likely to have extended LOS following hip replacements and knee replacements. Regional differences were noted in LOS between the Waitemata District Health Board (DHB) compared to Tairāwhiti DHB where patients were the most likely to have a LOS of more than 5 days after hip and knee replacements. LOS after hip and knee replacements has been reduced dramatically. Women, Māori, Pacific and Asian patients, older patients and people with more comorbidities are more likely to have extended LOS. Patients dispensed opiates on discharge had a longer LOS. There are great geographical variations in LOS for primary hip and knee surgeries in New Zealand.
\end{abstract}

Keywords: hip replacement; knee replacement; osteoarthritis; length of stay

\section{Introduction}

Osteoarthritis of the hip and knee is one of the most common causes of reduced mobility [1]. In New Zealand, osteoarthritis affects $10.6 \%$ of adults [2]. Hip and knee replacements for osteoarthritis can help alleviate pain and improve function. The New Zealand Joint Registry reports that osteoarthritis was responsible for $87 \%$ of primary hip arthroplasties and $84 \%$ of primary knee arthroplasties [3]. The number of hip and knee replacement surgeries in New Zealand has been increasing over time. There were 8785 primary hip replacement surgeries and 7765 primary knee replacement surgeries performed in 2016, compared to 4114 and 2429 in 1999, which poses an increasing burden to the healthcare system [3].

Hospital inpatient costs of arthritis were estimated to be NZ\$321 million in 2018, and they were dominated by osteoarthritic hip and knee surgeries [4]. Length of stay (LOS) for surgery plays an important role in the costs and the cost-effectiveness of hip and knee surgeries [5-8]. Reduced LOS following joint replacement surgery is a generalized trend around the world [7,9]. Decreased LOS 
is an indication of reduced costs and increased cost-effectiveness. In a UK study, the LOS dropped from 16.0 days in 1997 to 5.4 in 2014 for primary knee replacement, and from 14.4 to 5.6 for primary hip replacement, leading to savings of $£ 1537$ and $£ 1412$ per patient (without adjusting for inflation) over the 23 years [7]. A US study reported a cost saving of US $\$ 3245$ per patient for primary total knee arthroplasty after shortening the LOS by 0.7 days [8]. The public healthcare resources are limited and reduction of costs in joint replacement surgeries can lead to more resources for saving lives and improving quality of life in other health domains.

The New Zealand health care system is a mix of government funded and private health care. Publicly funded primary hip replacements accounted for $54 \%$ of the total number of all primary hip replacements in 2005-2016, and publicly funded primary knee replacements accounted for $59 \%$ of the total numbers of all primary hip replacements [3]. This study aims to explore the LOS of publicly funded osteoarthritic hip and knee replacement surgeries in New Zealand and to examine the factors that influence LOS.

\section{Methods}

This study included patients with osteoarthritis who underwent publicly funded primary hip and knee replacement surgery in 2005-2017 [10]. These records were identified from the National Minimum Dataset (NMD) that stores all publicly funded hospital inpatient and day-patient discharge information nationally. The ICD-10-AM ACHI Procedure Codes (Version 3) were used to extract the primary hip and knee replacement surgeries. These records were cross referenced with the New Zealand Joint Registry [3] data to exclude the admissions not for primary hip or knee replacement surgeries. The NMD also records patient's diagnosis for the admission and other comorbidities. Patients without a diagnosis of osteoarthritis were excluded. Comorbidities for calculating the Charlson comorbidity index score were identified from the diagnostic codes based on the coding algorithms developed by Quan et al. [11].

The PHARMS dataset was linked to the NMD through patients' National Health Index (NHI) numbers to identify the use of strong opiates after surgeries [12]. The NHI number is a unique identifier that is assigned to every person who uses health and disability support services in New Zealand. The PHARMS dataset stores all publicly funded pharmaceutical dispensing records. The strong opiates included in this study were dihydrocodeine tartrate, fentanyl citrate, fentanyl, methadone hydrochloride, morphine hydrochloride, morphine sulphate, morphine tartrate, oxycodone pectinate, oxycodone hydrochloride and pethidine hydrochloride.

We estimated the average LOS after surgery by gender, ethnicity (Māori, Pacific, Asian and European/others), age group ( $<40,40-49,50-59,60-69,70-79$ and $80+$ years), Charlson comorbidity index score (0, 1, 2 and 3+), year of surgery, use of opiate or not after surgery and District Health Board (DHB) where the surgery was performed. There are 20 DHBs in New Zealand. They are responsible for providing or funding the provision of health services in their district. The public hospitals where these joint replacement procedures are performed are owned and funded by DHBs. An independent-samples $t$-test and one-way ANOVA were used to compare the average LOS between subgroups. We used two definitions of extended LOS: (1) over 5 days and (2) over 7 days. A logistic regression model was used to examine the impact of all these factors on extended LOS and estimate the odds ratios after adjustment for age, gender, ethnicity, Charlson comorbidity index score, year of surgery, use of opiate or not after surgery and DHB. All data cleaning and analyses were performed in R 3.5.0 ( R Foundation For Statistical Computing, Vienna, Austria).

\section{Results}

We identified 53,439 publicly funded osteoarthritic primary hip replacement surgeries and 50,072 osteoarthritic primary knee replacements in 2005-2017 (Table 1). The numbers of hip and knee replacement surgeries have been increasing over time. Around $93 \%$ of primary hip replacements and $98 \%$ of primary knee replacements were performed in patients aged 50+ years. Slightly more 
hip and knee replacement surgeries were performed in women (54.3\% hips and 53.3\% knees) than in men. Māori were more likely to have primary hip replacement surgeries than knee replacement surgeries, but Asian and Pacific people were more likely to have knee replacement surgeries than hip replacement surgeries. The majority of patients had no severe comorbidities: $87.6 \%$ for hip surgeries and $85.1 \%$ for knee surgeries. Twenty-two percent of patients undergoing hip replacement surgeries and $30.5 \%$ of knee replacement patients had strong opiate drugs post operation.

Women had a longer LOS than men (5.3 vs. 4.7 days for hip surgeries and 5.4 vs. 5.1 after knee surgeries; Table 1). The LOS generally increased with age except for the age group of less than 40 years old. Māori patients had the shortest LOS than other ethnic groups. However, when we compared the LOS between ethnic groups after stratifying them by age group (Table 2), Māori and Pacific patients generally had longer LOS than Europeans and others by age group.

The LOS increased with Charlson score: from 4.8 days for score 0 to 8.3 days for score $3+$ for hip surgeries, and from 5.1 days for score 0 to 7.9 days for score $3+$ for knee surgeries (Table 1). Patients who had opiates after surgery had a longer LOS than those did not have opiates. The overall LOS has been decreasing over time: from 6.2 days in 2005 to 3.8 days in 2017 for hip surgeries, and from 6.6 days in 2005 to 4.1 days in 2017 for knee surgeries.

South Canterbury DHB (4.3 days) had the shortest LOS after hip surgeries (Table 3), followed by Nelson-Marlborough DHB (4.4 days) and Capital and Coast DHB (4.6 days). Tairāwhiti DHB (5.9 days), Auckland DHB (5.6 days) and Waikato DHB (5.5 days) had the longest LOS after hip surgeries. Nelson-Marlborough DHB (4.4 days) had the shortest LOS after knee surgeries, followed by Capital and Coast DHB (4.8 days) and South Canterbury DHB (4.8 days). Auckland DHB (6.0 days), Wairarapa DHB (5.9 days) and Tairāwhiti DHB (5.7 days) had the longest LOS after knee surgeries.

For primary hip replacement, $29.9 \%$ of patients had a LOS of more than 5 days and $10.5 \%$ had a LOS of more than one week. For primary knee replacement, 34.2\% of patients had a LOS of more than 5 days and $12.4 \%$ had a LOS of more than one week. Logistic regression (Tables 4 and 5) showed that after adjustment, women, Māori, Pacific and Asian patients, older patients, people with more comorbidities, those having opiates post operation and patients in earlier years were more likely to have extended LOS in terms of both hip surgeries and knee surgeries. Compared to Waitemata DHB, patients in Tairāwhiti DHB were the most likely to have a LOS of more than 5 days after hip and knee surgeries (odds ratio: 4.88 (95\% CI: 4.09-5.81) and 2.78 (95\% CI: 2.30-3.37) and the most likely to have a LOS of more than one week after hip surgeries (odds ratio: 3.13 (95\% CI: 2.53-3.86)). Compared to Waitemata DHB, patients in Auckland DHB were the most likely to have a LOS of more than 7 days after knee surgeries (odds ratio: 1.79 (95\% CI: 1.58-2.03). For hip surgeries, South Canterbury DHB was the least likely to have an extended LOS of more than 5 days (0.75 (95\% CI: $0.63-0.88)$ ), and of more than 7 days (0.46 (95\% CI: 0.35-0.61)). For knee surgeries, Nelson-Marlborough DHB was the least likely to have an extended LOS of more than 5 days (0.56 (95\% CI: $0.49-0.64)$ ), and of more than 7 days (0.45 (95\% CI: 0.36-0.55)). 
Table 1. Length of hospital stay by subgroup.

\begin{tabular}{|c|c|c|c|c|c|c|c|c|c|c|}
\hline \multirow{3}{*}{ Subgroup } & \multicolumn{5}{|c|}{ Primary Hip Replacement } & \multicolumn{5}{|c|}{ Primary Knee Replacement } \\
\hline & \multirow{2}{*}{ Number of Admissions } & \multicolumn{4}{|c|}{ LOS } & \multirow{2}{*}{ Number of Admissions } & \multicolumn{4}{|c|}{ LOS } \\
\hline & & Mean & Median & SD & $p$-Value & & Mean & Median & SD & $p$-Value \\
\hline \multicolumn{11}{|l|}{ Gender } \\
\hline Female & $29,015(54.3 \%)$ & 5.3 & 5 & 3.3 & $<0.001$ & $26,698(53.3 \%)$ & 5.4 & 5 & 2.6 & $<0.001$ \\
\hline Male & $24,424(45.7 \%)$ & 4.7 & 4 & 3.0 & & $23,374(46.7 \%)$ & 5.1 & 4 & 3.0 & \\
\hline \multicolumn{11}{|l|}{ Ethnicity } \\
\hline European/others & $46,347(86.7 \%)$ & 5.0 & 4 & 3.2 & $<0.001$ & $41,799(83.5 \%)$ & 5.3 & 5 & 2.8 & $<0.001$ \\
\hline Māori & $6071(11.4 \%)$ & 4.8 & 4 & 3.1 & & $3889(7.8 \%)$ & 5.1 & 5 & 2.8 & \\
\hline Pacific & $698(1.3 \%)$ & 5.0 & 4 & 3.5 & & $2477(4.9 \%)$ & 5.4 & 5 & 3.2 & \\
\hline Asian & $323(0.6 \%)$ & 5.3 & 4 & 3.7 & & $1907(3.8 \%)$ & 5.4 & 5 & 2.5 & \\
\hline \multicolumn{11}{|l|}{ Age } \\
\hline$<40$ & $771(1.4 \%)$ & 4.3 & 4 & 2.7 & $<0.001$ & $72(0.1 \%)$ & 5.1 & 5 & 3.0 & $<0.001$ \\
\hline $40-49$ & $3126(5.8 \%)$ & 4.2 & 4 & 3.0 & & $1130(2.3 \%)$ & 4.7 & 4 & 2.5 & \\
\hline 50-59 & $8733(16.3 \%)$ & 4.3 & 4 & 2.4 & & $7718(15.4 \%)$ & 4.7 & 4 & 2.3 & \\
\hline $60-69$ & $15,830(29.6 \%)$ & 4.6 & 4 & 2.6 & & $16,973(33.9 \%)$ & 4.9 & 4 & 2.4 & \\
\hline 70-79 & $17,645(33.0 \%)$ & 5.2 & 5 & 3.0 & & $17,969(35.9 \%)$ & 5.4 & 5 & 2.9 & \\
\hline $80+$ & $7341(13.7 \%)$ & 6.7 & 6 & 4.7 & & $6210(12.4 \%)$ & 6.5 & 6 & 3.5 & \\
\hline \multicolumn{11}{|c|}{ Charlson comorbidity index } \\
\hline 0 & $46,789(87.6 \%)$ & 4.8 & 4 & 2.8 & $<0.001$ & $42,603(85.1 \%)$ & 5.1 & 5 & 2.4 & $<0.001$ \\
\hline 1 & $3504(6.6 \%)$ & 6.1 & 5 & 4.1 & & $3781(7.6 \%)$ & 6.1 & 5 & 4.0 & \\
\hline 2 & $2213(4.1 \%)$ & 6.3 & 5 & 4.8 & & $2678(5.3 \%)$ & 6.2 & 5 & 3.7 & \\
\hline $3+$ & $933(1.7 \%)$ & 8.3 & 7 & 6.9 & & $1010(2.0 \%)$ & 7.9 & 7 & 5.2 & \\
\hline \multicolumn{11}{|c|}{ Use of opiate post-op } \\
\hline No & $41,500(77.7 \%)$ & 4.9 & 4 & 3.0 & $<0.001$ & $34,820(69.5 \%)$ & 5.2 & 5 & 2.7 & $<0.001$ \\
\hline Yes & $11,939(22.3 \%)$ & 5.6 & 4 & 3.8 & & $15,252(30.5 \%)$ & 5.6 & 5 & 2.9 & \\
\hline \multicolumn{11}{|l|}{ Year } \\
\hline 2005 & $3283(6.1 \%)$ & 6.2 & 6 & 3.2 & $<0.001$ & $3093(6.2 \%)$ & 6.6 & 6 & 3.5 & $<0.001$ \\
\hline 2006 & $3400(6.4 \%)$ & 6.1 & 6 & 3.7 & & $3155(6.3 \%)$ & 6.4 & 6 & 2.9 & \\
\hline 2007 & $3857(7.2 \%)$ & 6.1 & 5 & 3.3 & & $3573(7.1 \%)$ & 6.2 & 6 & 3.0 & \\
\hline 2008 & $3725(7.0 \%)$ & 5.9 & 5 & 3.8 & & $3347(6.9 \%)$ & 6.1 & 5 & 3.0 & \\
\hline 2009 & 3946 (7.4\%) & 5.6 & 5 & 3.1 & & $3538(7.1 \%)$ & 5.9 & 5 & 2.8 & \\
\hline 2010 & 3853 (7.2\%) & 5.5 & 5 & 3.6 & & $3438(6.9 \%)$ & 5.8 & 5 & 2.9 & \\
\hline 2011 & 3855 (7.2\%) & 5.2 & 5 & 2.7 & & $3623(7.2 \%)$ & 5.5 & 5 & 2.7 & \\
\hline 2012 & $4000(7.5 \%)$ & 4.9 & 4 & 3.1 & & $3818(7.6 \%)$ & 5.3 & 5 & 2.7 & \\
\hline 2013 & $4188(7.8 \%)$ & 4.6 & 4 & 2.9 & & $3750(7.5 \%)$ & 5.0 & 5 & 2.6 & \\
\hline 2014 & $4653(8.7 \%)$ & 4.4 & 4 & 2.9 & & $4481(8.9 \%)$ & 4.6 & 4 & 2.5 & \\
\hline 2015 & $4626(8.7 \%)$ & 4.2 & 4 & 2.8 & & $4349(8.7 \%)$ & 4.3 & 4 & 2.1 & \\
\hline 2016 & $4781(8.9 \%)$ & 4.0 & 3 & 2.9 & & $4644(9.3 \%)$ & 4.2 & 4 & 2.2 & \\
\hline 2017 & $5272(9.9 \%)$ & 3.8 & 3 & 2.4 & & $5263(10.5 \%)$ & 4.1 & 4 & 2.1 & \\
\hline Overall & 53,439 & 5.0 & 4 & 3.2 & & 50,072 & 5.3 & 5 & 2.8 & \\
\hline
\end{tabular}


Table 2. Length of hospital stay by ethnicity after stratifying by age group.

\begin{tabular}{|c|c|c|c|c|c|c|c|c|c|}
\hline \multirow{3}{*}{ Age } & \multirow{3}{*}{ Ethnicity } & \multicolumn{5}{|c|}{ Primary Hip Replacement } & \multirow{2}{*}{\multicolumn{3}{|c|}{$\begin{array}{c}\text { Primary Knee Replacement } \\
\text { LOS }\end{array}$}} \\
\hline & & \multirow{2}{*}{ Number of Admissions } & \multicolumn{3}{|c|}{ LOS } & \multirow{2}{*}{ Number of Admissions } & & & \\
\hline & & & Mean & Median & SD & & Mean & Median & SD \\
\hline \multicolumn{10}{|l|}{$<40$} \\
\hline & European/others & 524 & 4.1 & 4 & 2.3 & 52 & 5.3 & 5 & 3.2 \\
\hline & Māori & 169 & 4.3 & 4 & 3.5 & 9 & 5.7 & 5 & 2.9 \\
\hline & Pacific & 64 & 5.0 & 4 & 3.7 & 9 & 3.8 & 3 & 2.4 \\
\hline & Asian & 14 & 5.1 & 5 & 2.3 & 2 & 4.5 & 4.5 & 2.1 \\
\hline \multicolumn{10}{|l|}{$40-49$} \\
\hline & European/others & 2156 & 4.2 & 4 & 3.0 & 817 & 4.7 & 4 & 2.6 \\
\hline & Māori & 784 & 4.3 & 4 & 3.1 & 191 & 4.7 & 4 & 2.4 \\
\hline & Pacific & 138 & 4.0 & 4 & 1.9 & 95 & 4.6 & 4 & 1.7 \\
\hline & Asian & 48 & 4.3 & 4 & 2.0 & 27 & 5.6 & 5 & 2.8 \\
\hline \multicolumn{10}{|l|}{$50-59$} \\
\hline & European/others & 6721 & 4.2 & 4 & 2.2 & 5740 & 4.6 & 4 & 2.0 \\
\hline & Māori & 1740 & 4.3 & 4 & 2.8 & 1069 & 4.7 & 4 & 2.8 \\
\hline & Pacific & 208 & 4.7 & 4 & 3.6 & 623 & 5.0 & 4 & 3.7 \\
\hline & Asian & 63 & 5.4 & 5 & 5.0 & 286 & 5.3 & 5 & 2.5 \\
\hline \multicolumn{10}{|l|}{$60-69$} \\
\hline & European/others & 13,597 & 4.6 & 4 & 2.6 & 13,600 & 4.8 & 4 & 2.3 \\
\hline & Māori & 1997 & 4.7 & 4 & 3.0 & 1533 & 5.0 & 4 & 2.7 \\
\hline & Pacific & 149 & 5.4 & 5 & 3.9 & 1045 & 5.3 & 5 & 2.5 \\
\hline & Asian & 86 & 5.0 & 4 & 2.8 & 795 & 5.3 & 5 & 2.3 \\
\hline \multicolumn{10}{|l|}{$70-79$} \\
\hline & European/others & 16,237 & 5.2 & 5 & 3.0 & 15,723 & 5.4 & 5 & 2.9 \\
\hline & Māori & 1201 & 5.5 & 5 & 3.2 & 937 & 5.6 & 5 & 2.8 \\
\hline & Pacific & 118 & 5.9 & 5 & 3.6 & 636 & 6.0 & 5 & 3.8 \\
\hline & Asian & 86 & 5.8 & 5 & 3.7 & 673 & 5.5 & 5 & 2.5 \\
\hline \multicolumn{10}{|l|}{$80+$} \\
\hline & European/others & 7112 & 6.7 & 6 & 4.7 & 5867 & 6.5 & 6 & 3.5 \\
\hline & Māori & 180 & 6.4 & 6 & 4.4 & 150 & 6.4 & 6 & 3.1 \\
\hline & Pacific & 21 & 6.8 & 6 & 4.5 & 69 & 6.6 & 5 & 3.7 \\
\hline & Asian & 26 & 7.0 & 5 & 5.0 & 124 & 6.2 & 5 & 2.9 \\
\hline
\end{tabular}


Table 3. Length of hospital stay by DHB.

\begin{tabular}{|c|c|c|c|c|c|c|c|c|}
\hline \multirow{3}{*}{ DHB } & \multicolumn{5}{|c|}{ Primary Hip Replacement } & \multirow{2}{*}{\multicolumn{3}{|c|}{$\begin{array}{c}\text { Primary Knee Replacement } \\
\text { LOS }\end{array}$}} \\
\hline & \multirow{2}{*}{ Number of Admissions } & \multicolumn{3}{|c|}{ LOS } & \multirow{2}{*}{ Number of Admissions } & & & \\
\hline & & Mean & Median & SD & & Mean & Median & SD \\
\hline Northland & 2521 & 5.1 & 5 & 3.4 & 2396 & 5.6 & 5 & 2.9 \\
\hline Waitemata & 5021 & 4.7 & 4 & 2.8 & 600 & 5.0 & 4 & 3.4 \\
\hline Auckland & 2630 & 5.6 & 5 & 4.9 & 3331 & 6.0 & 5 & 3.2 \\
\hline Counties Manukau & 4064 & 4.9 & 4 & 3.1 & 5395 & 5.3 & 5 & 3.2 \\
\hline Waikato & 4965 & 5.5 & 5 & 3.5 & 4731 & 5.6 & 5 & 2.9 \\
\hline Lakes & 1581 & 4.7 & 4 & 2.7 & 1449 & 4.9 & 4 & 2.6 \\
\hline Bay of Plenty & 3834 & 5.3 & 5 & 3.6 & 3375 & 5.4 & 5 & 3.0 \\
\hline Tairāwhiti & 786 & 5.9 & 5 & 4.5 & 572 & 5.7 & 6 & 2.4 \\
\hline Hawkes Bay & 2338 & 5.1 & 5 & 3.1 & 2050 & 5.1 & 5 & 2.5 \\
\hline Taranaki & 1725 & 5.3 & 5 & 3.7 & 1202 & 5.6 & 5 & 2.9 \\
\hline Mid Central & 2390 & 4.9 & 4 & 2.5 & 2275 & 5.0 & 4 & 2.2 \\
\hline Whanganui & 1357 & 5.1 & 4 & 2.8 & 1264 & 4.9 & 4 & 2.5 \\
\hline Capital and Coast & 2561 & 4.6 & 4 & 3.1 & 2696 & 4.8 & 4 & 2.3 \\
\hline Hutt Valley & 1539 & 4.9 & 5 & 2.6 & 1551 & 5.1 & 5 & 2.5 \\
\hline Wairarapa & 764 & 5.2 & 5 & 2.8 & 666 & 5.9 & 5 & 2.9 \\
\hline Nelson-Marlborough & 2655 & 4.4 & 4 & 2.3 & 2108 & 4.4 & 4 & 2.0 \\
\hline West Coast & 709 & 5.1 & 5 & 2.3 & 665 & 5.4 & 5 & 2.3 \\
\hline Canterbury & 6081 & 4.8 & 4 & 2.8 & 4255 & 5.0 & 5 & 2.1 \\
\hline South Canterbury & 1327 & 4.3 & 4 & 2.3 & 999 & 4.8 & 4 & 2.7 \\
\hline Southern & 4558 & 5.2 & 5 & 2.8 & 3068 & 5.6 & 5 & 2.6 \\
\hline Unknown & 33 & 5.8 & 5 & 3.3 & 24 & 5.3 & 5 & 1.6 \\
\hline Overall & 53,439 & 5.0 & 4 & 3.2 & 5072 & 5.3 & 5 & 2.8 \\
\hline
\end{tabular}


Table 4. Adjusted odds ratio of length of stay over 5 days and 7 days after hip replacement surgeries. ${ }^{\dagger}$.

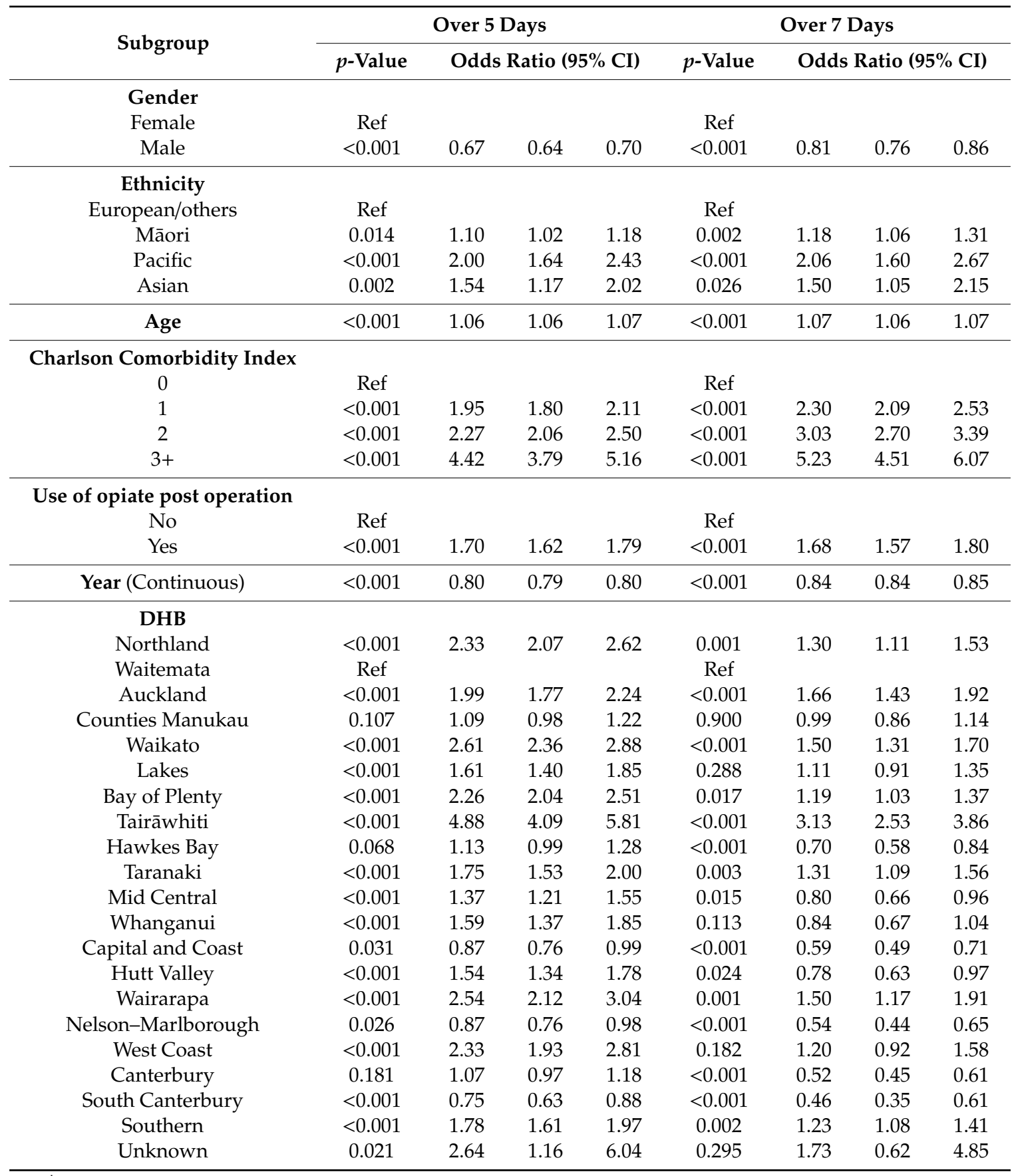

${ }^{+}$Adjusted for age, gender, ethnicity, Charlson comorbidity index score, year of surgery, use of opiate or not after surgery and DHB. 
Table 5. Adjusted odds ratio of length of stay over 5 days and 7 days after knee replacement surgeries. ${ }^{\dagger}$.

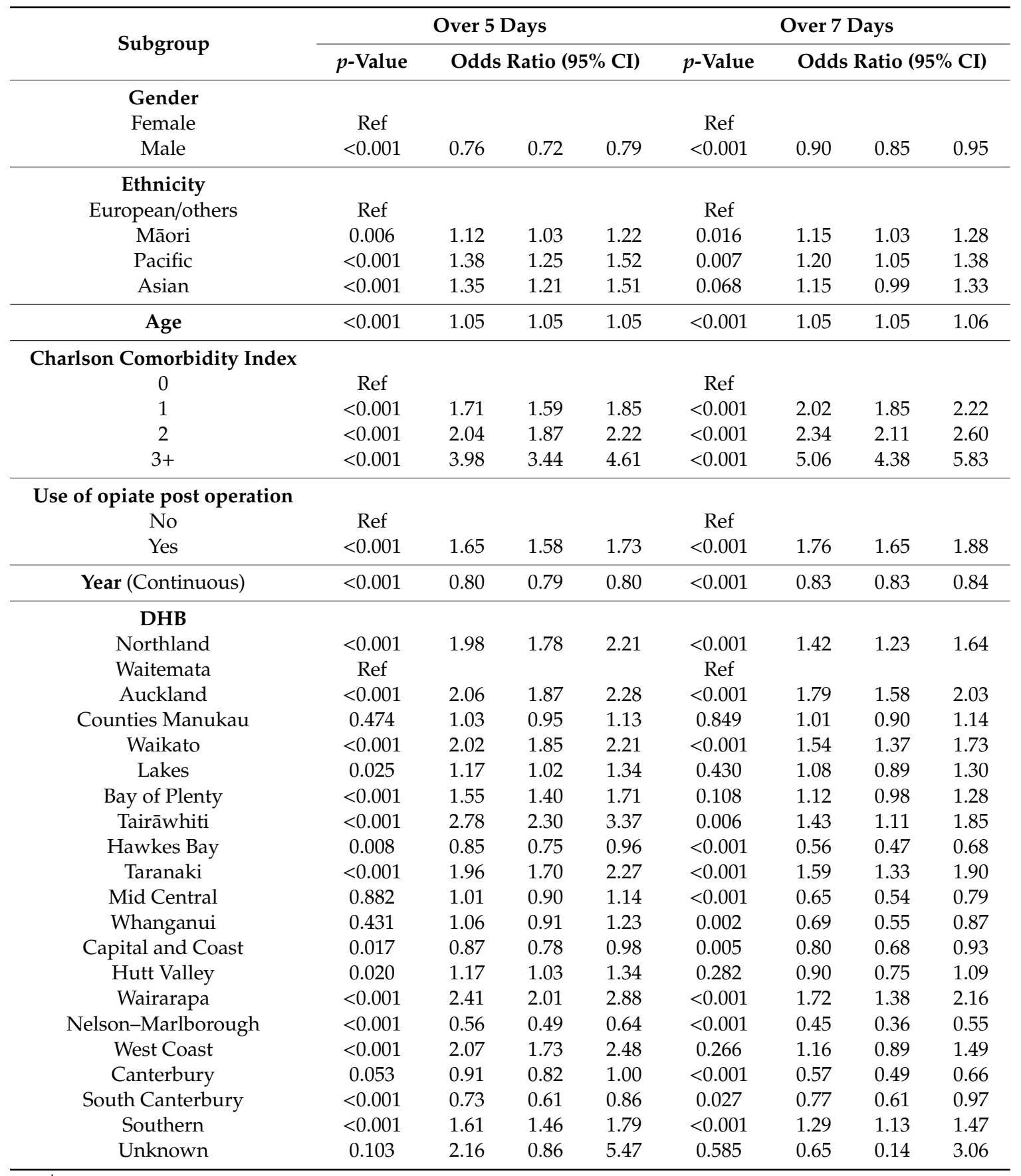

${ }^{\dagger}$ Adjusted for age, gender, ethnicity, Charlson comorbidity index score, year of surgery, use of opiate or not after surgery and DHB.

\section{Discussions}

The average LOS was reduced by 2.4-2.5 days for primary hip and knee replacement surgeries over the 13 years period (from 2005 to 2017), leading to a cost reduction of approximately NZ\$4000 per surgical case that is $13 \%-20 \%$ of the total cost $[13,14]$. The total cost savings for all the publicly funded primary hip and knee replacement surgeries in 2017 were approximately 42 million New Zealand dollars due to the reduced LOS.

Overseas studies demonstrated the same time trend of LOS following total hip and knee replacement $[7,9]$. The average LOS in the UK in 2014 was 5.6 days for primary hip replacement and 5.4 days for primary knee replacement, which were both slightly longer than in NZ: 4.4 days and 
4.6 days respectively. However, the LOS in the US is even shorter: 2.75 days for hip replacement and 2.95 days for knee replacement in 2013 [9].

Improved processes have been shown to reduce LOS [7]. Protocols with an emphasis on recovery and rehabilitation have been introduced in elective orthopedics, including 'Accelerated Rehabilitation', 'Fast-Track', 'Clinical Pathways' and "Enhanced Recovery After Surgery (ERAS)” programs [15-17]. Many of these programs have been introduced to New Zealand and have contributed to the reduced LOS $[18,19]$. The LOS for hip and knee replacements could reduce further, with outpatient hip and knee replacement surgeries being possible. A US study found that 1-day LOS discharge after total hip and knee replacement is achievable and did not increase readmissions compared to 2-day LOS discharge [20].

A key component of every enhanced recovery protocol is the use of multimodal (opioid-sparing) analgesia involving a combination of different opioid and non-opioid analgesic and non-analgesic drugs [21]. Multimodal analgesia can reduce postoperative side effects and therefore facilitate the recovery process after surgery [22]. This study showed that patients who used opiates after hip and knee surgery had a longer LOS. This may represent higher levels of post-operative pain as well as the higher levels of inpatient opiate use influencing LOS.

Age at surgery, comorbidities, low income, obesity and female gender have been reported to be associated with increased LOS [5-7,23-25]. In our study, women had a longer LOS than men, which was consistent with other studies $[6,26,27]$. This could be attributed to differences in ways in which men and women respond to the disease, anesthesia and the surgery or to bias on the part of healthcare workers $[6,26,27]$. As expected, the LOS increased with age, because older patients have more comorbidities and have slower recovery after surgery. It has also been found that older patients were more likely to have experienced post-operative complications, admission to the intensive care unit (ICU) and be discharged to a skilled care facility [28]. Asian, Pacific and Māori patients were more likely to have an extended LOS of more than 5 days and 7 days than European/others after adjustment for other factors. This may be also related to differences in comorbidities in these groups. In this cohort, $27 \%$ of Asian patients, $26 \%$ of Pacific patients and $20 \%$ of Māori patients had at least one comorbidity, compared to $12 \%$ European/others. Other reasons may include the prevalence of obesity in Māori and Pacific patients [29]. Obesity is associated with a longer LOS after joint replacements [30].

There are great geographical variations in LOS after primary hip and knee surgeries in New Zealand. This may be partially explained by the differences in medical centers and the populations in different DHBs. Expert orthopaedic surgeons in big DHBs may have a shorter length of operation than generalist orthopaedic surgeons in small DHBs. Length of operation has been shown to increase the risk of a major complication, resulting in an increased LOS [31]. The Auckland DHB had a high Pacific population (10.3\% vs. $6.5 \%$ for the national population), and the Tairāwhiti and Waikato DHB had a high Māori population (50.3\% and $22.8 \%$ vs. $15.7 \%$ for the national population) [32]. The Nelson-Marlborough and South Canterbury DHB have an older and rural population with lower Māori and Pacific populations [32].

The strength of this study was that it was based on national datasets including over 100,000 primary hip and knee replacement surgeries. These datasets collect comprehensive data on patient characteristics, comorbidities and post discharge pharmaceutical dispensing [10]. One weakness is that this study did not include certain clinical information, e.g., pre- and postoperative hemoglobin levels and blood transfusions, which have been found to influence LOS [27]. Another limitation is that some peripheral centers without specialized services such as an ICU or access to dialysis transfer their high risk and dialysis patients to a tertiary centre for their surgery or post-op management, which is likely to influence the LOS but we could not identify these cases. Similarly, we could not identify whether some hospitals had skilled nursing facilities or extended rehabilitation facilities, which would affect the LOS. We had no data on social determinants such as whether some patients (such as women) were more likely to live alone or live without social support might need longer hospital LOS. 


\section{Conclusions}

LOS has been reduced by almost $40 \%$ over the last 13 years, which poses a major cost saving to the public health system. Women, Māori, Pacific and Asian patients, older patients, people with more comorbidities and patients in earlier years were more likely to have extended LOS. Patients dispensed opiates on discharge had a longer LOS. Finally we found there were great geographical variations in LOS for primary hip and knee surgeries in New Zealand, which was likely to be multifactorial. LOS might reduce further with outpatient surgeries being possible and enhancement in the current recovery and rehabilitation programs.

Author Contributions: C.L., D.L., R.L., D.W. and S.P. conceived of and designed the study. C.L. did all the data cleaning and analyses, and wrote the first draft of the main paper. All the authors discussed the results and were involved in the critical revisions of the manuscript. All the authors have read and approved the final version of the manuscript.

Funding: This study was funded by Lottery Health Research (Project number: 106082). The funder was not involved in any part of this study.

Acknowledgments: We would like to thank the Lottery Health Research for funding this study, and the New Zealand Joint Registry for providing the data for validation.

Conflicts of Interest: The authors declare no conflict of interest.

\section{References}

1. Vos, T.; Flaxman, A.D.; Naghavi, M.; Lozano, R.; Michaud, C.; Ezzati, M.; Shibuya, K.; Salomon, J.A.; Abdalla, S.; Aboyans, V.; et al. Years lived with disability (YLDs) for 1160 sequelae of 289 diseases and injuries 1990-2010: A systematic analysis for the Global Burden of Disease Study 2010. Lancet 2012, 380, 2163-2196. [CrossRef]

2. Ministry of Health. Annual Data Explorer 2017/18: New Zealand Health Survey. 2019 [cited 201926 June 2019]. Available online: https://minhealthnz.shinyapps.io/nz-health-survey-2017-18-annual-data-explorer/ _W_0811ceee/_W_e98adb87/\#!/home (accessed on 5 May 2019).

3. New Zealand Orthopaedic Association. The New Zealand Joint Registry 17 Year Report; New Zealand Orthopaedic Association: Wellington, New Zealand, 2016.

4. Deloitte Access Economics. The Economic Cost of Arthritis in New Zealand in 2018; Deloitte Access Economics: Wellington, New Zealand, 2018.

5. Jane, H.H.; Cleary, R.; Gillespie, W.J.; Pinder, I.M.; Sher, J.L. Are clinical and patient assessed outcomes affected by reducing length of hospital stay for total hip arthroplasty? J. Arthroplast. 2000, 15, 448-452.

6. Abbas, K.; Umer, M.; Qadir, I.; Zaheer, J.; ur Rashid, H. Predictors of length of hospital stay after total hip replacement. J. Orthop. Surg. (Hong Kong) 2011, 19, 284-287. [CrossRef]

7. Burn, E.; Edwards, C.J.; Murray, D.W.; Silman, A.; Cooper, C.; Arden, N.K.; Pinedo-Villanueva, R. Prieto-Alhambra, D. Trends and determinants of length of stay and hospital reimbursement following knee and hip replacement: Evidence from linked primary care and NHS hospital records from 1997 to 2014. BMJ Open 2018, 8, e019146. [CrossRef]

8. Barad, S.J.; Howell, S.M.; Tom, J. Is a shortened length of stay and increased rate of discharge to home associated with a low readmission rate and cost-effectiveness after primary total knee arthroplasty? Arthroplast. Today 2018, 4, 107-112. [CrossRef]

9. Molloy, I.B.; Martin, B.I.; Moschetti, W.E.; Jevsevar, D.S. Effects of the Length of Stay on the Cost of Total Knee and Total Hip Arthroplasty from 2002 to 2013. J. Bone Joint. Surg. Am. 2017, 99, 402-407. [CrossRef]

10. Chunhuan, L.; David, L.; Sandeep, P.; Douglas, W.; Ross, L. Geographical and ethnic differences of osteoarthritis-associated hip and knee replacement surgeries in New Zealand: A population-based cross-sectional study. BMJ Open 2019, 9, e032993.

11. Quan, H.; Sundararajan, V.; Halfon, P. Andrew Fong Coding algorithms for defining comorbidities in ICD-9-CM and ICD-10 administrative data. Med. Care 2005, 43, 1130-1139. [CrossRef]

12. Ministry of Health. National Collections and Surveys. 2017. Available online: http://www.health.govt.nz/nzhealth-statistics/national-collections-and-surveys (accessed on 5 May 2019). 
13. Southern Cross. Total Hip Joint Replacement Surgery. 2017. Available online: https://www.southerncross.co. nz/group/medical-library/total-hip-joint-replacement-surgery (accessed on 5 May 2019).

14. Southern Cross. Total Knee Joint Replacement Surgery. 2017. Available online: https://www.southerncross. co.nz/group/medical-library/total-knee-joint-replacement-surgery (accessed on 5 May 2019).

15. Kehlet, H. Fast-track hip and knee arthroplasty. Lancet 2013, 381, 1600-1602. [CrossRef]

16. Maempel, J.F.; Walmsley, P.J. Enhanced recovery programmes can reduce length of stay after total knee replacement without sacrificing functional outcome at one year. Ann. R. Coll. Surg. Engl. 2015, 97, 563-567. [CrossRef]

17. Stowers, M.D.; Manuopangai, L.; Hill, A.G.; Gray, J.R.; Coleman, B.; Munro, J.T. Enhanced Recovery After Surgery in elective hip and knee arthroplasty reduces length of hospital stay. ANZ J. Surg. 2016, 86, 475-479. [CrossRef]

18. Tarik, S.; Kamran, Z.S.; Abhijith, B.; Arman, K.; Andrew, G.H. A programme of Enhanced Recovery After Surgery (ERAS) is a cost-effective intervention in elective colonic surgery. N. Z. Med. J. 2010, 123, 61-70.

19. Lemanu, D.P.; Singh, P.P.; Berridge, K.; Burr, M.; Birch, C.; Babor, R.; MacCormick, A.D.; Arroll, B.; Hill, A.G. Randomized clinical trial of enhanced recovery versus standard care after laparoscopic sleeve gastrectomy. Br. J. Surg. 2013, 100, 482-489. [CrossRef]

20. Sibia, U.S.; Waite, K.A.; Callanan, M.A.; Park, A.E.; King, P.J.; MacDonald, J.H. Do shorter lengths of stay increase readmissions after total joint replacements? Arthroplast. Today 2017, 3, 51-55. [CrossRef]

21. White, P.F. Expanding role of multimodal analgesia in facilitating recovery after surgery: From fast-tracking to enhanced recovery. J. Clin. Anesth. 2019, 55, 105-107. [CrossRef]

22. Chen, J.Y.; Ko, T.L.; Wen, Y.R.; Wu, S.C.; Chou, Y.H.; Yien, H.W.; Kuo, C.D. Opioid-sparing effects of ketorolac and its correlation with the recovery of postoperative bowel function in colorectal surgery patients: A prospective randomized double-blinded study. Clin. J. Pain 2009, 25, 485-489. [CrossRef]

23. Epps, C.D. Length stay, discharge disposition, and hospital charge predictors. AORN J. 2004, 79, 975-976. [CrossRef]

24. Batsis, J.A.; Naessens, J.M.; Keegan, M.T.; Wagie, A.E.; Huddleston, P.M.; Huddleston, J.M. Impact of body mass on hospital resource use in total hip arthroplasty. Public Health Nutr. 2009, 12, 1122-1132. [CrossRef]

25. El Bitar, Y.F.; Illingworth, K.D.; Scaife, S.L.; Horberg, J.V.; Saleh, K.J. Hospital Length of Stay following Primary Total Knee Arthroplasty: Data from the Nationwide Inpatient Sample Database. J. Arthroplast. 2015, 30, 1710-1715. [CrossRef]

26. Butterworth, J.; James, R.; Prielipp, R.; Cerese, J.; Livingston, J.; Burnett, D. Female gender associates with increased duration of intubation and length of stay after coronary artery surgery. CABG Clinical Benchmarking Database Participants. Anesthesiology 2000, 92, 414-424. [CrossRef]

27. Husted, H.; Holm, G.; Jacobsen, S. Predictors of length of stay and patient satisfaction after hip and knee replacement surgery: Fast-track experience in 712 patients. Acta Orthop. 2008, 79, 168-173. [CrossRef]

28. Fang, M.; Noiseux, N.; Linson, E.; Cram, P. The Effect of Advancing Age on Total Joint Replacement Outcomes. Geriatr. Orthop. Surg. Rehabil. 2015, 6, 173-179. [CrossRef]

29. Ministry of Health of New Zealand. Annual Data Explorer 2017/18: New Zealand Health Survey [Data File]; Ministry of Health: Wellington, New Zealand, 2019.

30. Maradit Kremers, H.; Visscher, S.L.; Kremers, W.K.; Naessens, J.M.; Lewallen, D.G. Obesity increases length of stay and direct medical costs in total hip arthroplasty. Clin. Orthop. Relat. Res. 2014, 472, 1232-1239. [CrossRef]

31. O'Malley, N.T.; Fleming, F.J.; Gunzler, D.D.; Messing, S.P.; Kates, S.L. Factors independently associated with complications and length of stay after hip arthroplasty: Analysis of the National Surgical Quality Improvement Program. J. Arthroplast. 2012, 27, 1832-1837. [CrossRef]

32. Ministry of Health of New Zealand. New Zealand Health System. 2018 [cited 201910 July]. Available online: https://www.health.govt.nz/new-zealand-health-system (accessed on 5 May 2019).

(C) 2019 by the authors. Licensee MDPI, Basel, Switzerland. This article is an open access article distributed under the terms and conditions of the Creative Commons Attribution (CC BY) license (http://creativecommons.org/licenses/by/4.0/). 